Maciej Talaga \& Harrison Ridgeway

\title{
Historical Visuals and Reconstruction of Motion: A Gestalt Perspective on Medieval Fencing Iconography
}

\section{Introduction}

Several subdisciplines within historiography are interested in inferring the physical qualities of historical material objects from historical sources. Scholars from these fields face serious deficiency of written accounts when it comes to various crucial information regarding their subject matter (Tilley, 2014). Especially measurements, dynamic properties and past functionalities of objects, such as tools, garments, weapons or even human physical bodies, are seldom communicated clearly and unambiguously in historical texts (Burkart, 2016). Therefore, researchers' attention is often drawn to iconographical sources, sometimes resulting in certain fascination with the materiality depicted in the primary technical literature (Fachliteratur), such as treatises on crafts or arts. This tendency seems particularly strong in studies on historical European martial arts (HEMA) which rely heavily on pre-modern treatises known as 'fight books' (Fechtbücher) (Jaquet, 2016). Historical visual representations of material culture are known to follow artistic conventions (Żygulski, 1984), while various compromises between naturalism and schematism were also forced by the limitations of the artistic media - for instance, mostly due to their small size, stove tiles would seldom enable detailed and naturalistic representation of arms and armour (Ławrynowicz \& Nowakowski, 2009). Other works show that images in fight books could play purely decorative or prestigious roles (Kleinau, 2016), in some cases even being copied into other works independently from captions thus forming 'a tradition of images rather than a tradition of text' (Farrell, 2017:225). Such an apparent mismatch between iconographical representations and their textual or material source domain is often interpreted as evidence for inadequacies on the part of the illustrator - either their subpar artistic skills, negligence or lack of understanding of the substance of the work they illustrated (Kleinau, 2016). This, in turn, undermines the credibility of iconography as a reliable source of knowledge about historical somatic practices.

Somewhat perversely and against their intended meaning, we would like to use the words of merited Polish art historian and arms and armour scholar, Zdzisław Żygulski - 'the basic aim of any art is not so much the portrayal of reality as the transfer of ideas' (Żygulski, 1984:77) - to propose a different perspective 
on the abovementioned inadequacies, distortions and modifications of artwork in the fight books. Instead of interpreting them as merely failed attempts at representing reality or results of convention or schematism, we hypothesise that in the context of the works in which they were included the distorted images may have a pragmatic function tightly related to their intended purpose - that is, transfer of somatic skills or 'embodied knowledge' (Spatz, 2015:1). Drawing from the Gestalt theory's principle of holism, we expect that the distortions seen in particular details do not automatically distort the whole image, just as the presence of some distorted words does not necessarily render the whole manuscript illegible.

\section{Static and Dynamic Gestalten}

Before we proceed with describing our case studies, it is necessary to clarify certain idiosyncrasies of our source base and its relation to the Gestalt conceptual framework. In our investigation, we used illustrations in fight books as examples of visual representations of motion created by, or under supervision of, expert practitioners (martial arts masters) as a way to mediate (transfer and preserve) somatic knowledge. Such representations had to face a major challenge - the discrepancy between the static nature of the media (drawings or paintings) and the dynamic nature of the content (martial arts techniques). Creating an adequate idea about motion in the recipient this way seems impossible without violating the Gestalt principle of isomorphism (Lehar, 1999) since the pattern of brain activity involved in motor tasks does not easily match that of the static stimulus array. Unlike the phi phenomenon or beta movement effect (Steinman, Pizlo, \& Pizlo, 2000), the fight book illustrations evoke the impression of motion and inform kinaesthetic practice through the use of still images with no traces of illusory motion devices. This suggests that, if this phenomenon is to be approachable in Gestalt terms at all, a sort of dynamic reformulation would be needed.

In this context, an interesting trope comes from the studies on interaction design the concept of the dynamic Gestalt. Writing about designing user experiences in digital environments, Löwgren and Stolterman (2004) noticed that ' $[\mathrm{w}]$ hen you use a digital artefact, you do things, the artefact responds, you act back, and so on. It is an unfolding story. The artefact gradually reveals its dynamic gestalt (...). Gestalt can be understood as the overall image, the emergent dynamic whole, something changing over time' (p. 53) which 'can only be apprehended by using it' (p. 138). Similarly to interactions with digital artefacts, to read the motion encoded in fight book illustrations means to use them - that is, to perform their kinaesthetic content. This, in turn, fits quite well with Fritz Heider's notion of 'reconstruction', as it requires the 'reader' to 'reconstruct the coordinated core 
event [i.e. martial arts technique] from the offshoots [i.e. images]' (Heider, 1959:26). Therefore, we may further hypothesise that while the static form of the investigated images cannot be directly reflected by brain activity responsible for bodily motion, some mechanisms hardwired in human cognitive processes enable bridging this gap by subconsciously complementing the static stimulus with its 'required' dynamic component (for more on the concept of 'requiredness', see Köhler, 1938).

\section{Sources}

To test our hypotheses, we performed two comparative case studies on latemedieval fight books. The first involved within-case analyses of two related 15th-cent. Manuscripts - Fior di Battaglia (MS XV 13) by Fiore de'i Liberi, dated to ca. 1404, and the anonymous fight book (Cod.5278), dated to the 1420s which contain variously distorted images of fencing techniques. For the other, we selected a pair of 15th- and 16th-cent. manuscripts - the second volume of Opus Amplissimum de Arte Athletica (Cod.icon. 393) by Paulus Hector Mair, dated to ca. 1540, and the untitled manuscript (Cgm 1507) by Paulus Kal, dated to ca. 1470 - which were then subjected to a comparative analysis tracing how images were transformed while copied between the works.

\section{Method}

The first case study involved select images from both manuscripts - Fior di Battaglia and Die Blume des Kampfes - which showed signs of distortions. Any kind of skewed proportions, awkward use of perspective, inconsistencies or other features of the images which could not be considered naturalistic representations of material reality were considered 'distortions'. A total of 19 images were chosen this way - nine from Fior di Battaglia (fols. 22r, 26r-v, 28r, 29r-v) and 10 from Die Blume des Kampfes (fols. 179r, 183r, 184r, 198r, 199r, 200r, 201r). All the images were subjected to qualitative coding to trace any potential patterns in the use of distortions.

For the second case study, 10 images were identified as copied from Kal's fight book to Mair's. In addition, another of Mair's illustrations was included to exemplify how images were altered while copied by the same person - Jörg Breu - from older sources to a draftbook and then to the actual books (Figs. 5 and 6). This gives a total of eleven pairs of images (Table 1). All the pairs were subjected to qualitative coding to trace any potential patterns in their differences and similarities.

\section{Distortions as Media for Knowledge Transmission}

Both manuscripts subjected to this analysis date to within a few decades of one another at the beginning of the fifteenth century, and exhibit a non-trivial 
Table 1. Pairs of model images from Paulus Kal's fight book and Jörg Breu’s draftbook tabulated with their copies in Mair's martial arts compendium. Source: M. Talaga (Author).

\begin{tabular}{lll}
\hline Pair & Model (folio; reference) & Copy (folio; reference) \\
\hline$\# 1$ & folio 55r; Paulus Kal, n.d. & folio 79v; Paulus Hector Mair, n.d. \\
$\# 2$ & folio 54v; Paulus Kal, n.d. & folio 79r; Paulus Hector Mair, n.d. \\
\#3 & folio 52v; Paulus Kal, n.d. & folio 77r; Paulus Hector Mair, n.d. \\
\#4 & Bayerische Staatsbibliothek & folio 67v; Paulus Hector Mair, n.d. \\
& München, Cgm 3712, fol. 197v & \\
\#5 & folio 53r; Paulus Kal, n.d. & folio 77v; Paulus Hector Mair, n.d. \\
\#6 & folio 53v; Paulus Kal, n.d. & folio 78r; Paulus Hector Mair, n.d. \\
$\# 7$ & folio 54r; Paulus Kal, n.d. & folio 78v; Paulus Hector Mair, n.d. \\
$\# 8$ & folio 55v; Paulus Kal, n.d. & folio 80r; Paulus Hector Mair, n.d. \\
$\# 9$ & folio 56r; Paulus Kal, n.d. & folio 80v; Paulus Hector Mair, n.d. \\
$\# 10$ & folio 56v; Paulus Kal, n.d. & folio 81r; Paulus Hector Mair, n.d. \\
\#11 & folio 57r; Paulus Kal, n.d. & folio 81v; Paulus Hector Mair, n.d. \\
\hline & &
\end{tabular}

degree of content overlap, which suggests that either both originate from a common source or one was copied from the other. The select illustrations exhibit clear and deliberate distortions which significantly compromise their visual realism. However, there are certain examples where the artist has succeeded in approximating a naturalistic representation of the subject (Fig. 1), usually through investing greater effort in the production of the image (indicated by clearer linework, deliberate shading, finer details and corrected errors). Since one of the discussed manuscripts is supposedly a modern copy (Fior di Battaglia, n.d.), such distortions could be interpreted as introduced either by the original illustrator or a copyist incompetent in the martial content of the book. In both scenarios, the most obvious explanation would be to treat the distorted images as evidence for subpar skills or learned schematism of their author. However, such discrepancy between the informative value of the text and illustrations would be puzzling in a fight book, that is a piece of Fachliteratur which, if illustrated at all, would deserve being illustrated well (Basing, 1990). Therefore, we would like to propose a different perspective - that these distortions were made, or perhaps left uncorrected, deliberately.

A comparison of the frequency of codes between the investigated images shows an interesting pattern (Fig. 2). While the images from Fior di Battaglia have 3.44 codes on average (median=3), those from Cod.5278 have an average of 6.20 (median=6), which means that the latter has significantly more distortions per image. Moreover, although both fight books have rather primitive images 
(coded as sketchy), Fior di Battaglia, unlike the other manuscript, has one image of outstanding quality (fine) and overall shows better, less disorganised artwork (in particular, it has no corrections). But most interestingly, this discrepancy in artwork quality seems to correlate with the somatic content of the images - while distorted images from Fior di Battaglia show almost exclusively sword-fighting

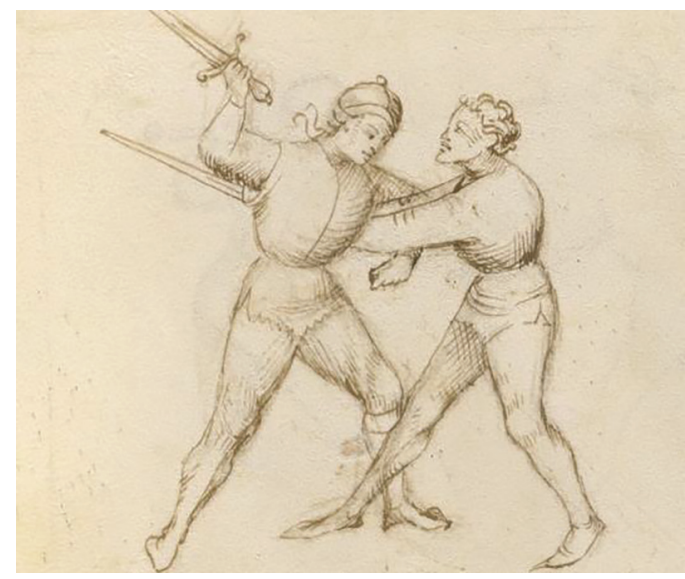

Fig. 1: Two-handed sword disarming technique performed with the left hand. It was coded as fine because it stands out from the rest of the images from this source in terms of artwork quality especially visible in the faces, shading and details of the sword hilt. At the same time, it seems distorted (shorter sword haft), since the sword raised by the left fighter appears to have room for just one hand on the haft, whereas the technique belongs to the section dedicated to fighting with twohanded swords - as clearly shown by the right fighter who is wielding his weapon with both hands. Sources: J. Paul Getty Museum, Los Angeles, California: digital image courtesy of the Getty's Open Content Programme.
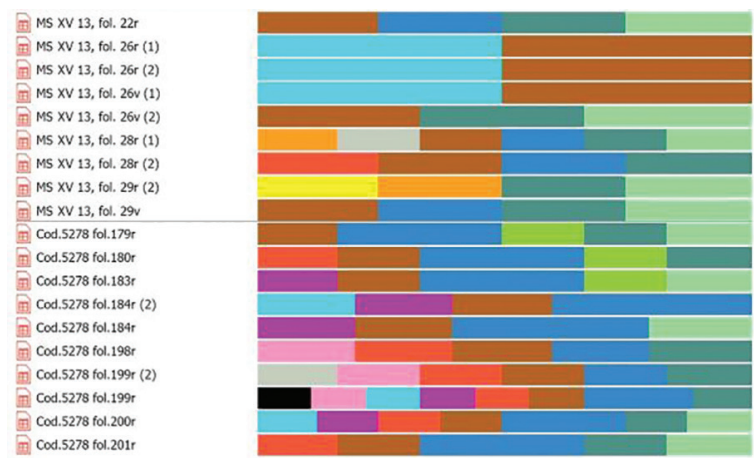

Fig. 2: Distribution of select codes in the distorted images from Fior di Battaglia (MS XV 13) by Fiore de'i Liberi and the anonymous fight book (Cod.5278). Key to colours: dark blue: point or pommel; light blue: shorter_sword; light green: longer_sword; green: correction; dark green: sword; purple: haft; pink: body; brown: sketchy; yellow: fine; grey: large_spacing; black: no_spacing; orange: hand_lock. Author: M. Talaga. 
techniques in which opponents are usually presented a sword-length apart, more than a half of selected illustrations in Cod.5278 present close quarter combat (wrestling). ${ }^{1}$ In consequence, Cod.5278 has three images with clear distortions applied to bodies (arms) of the depicted fighters (body), whereas in Fior di Battaglia only the weapon is affected (sword or haft). This would also explain the greater average number of distortions - with bodies and weapons of fighters entangled so close to each other it was challenging for the illustrator to find a satisfactory middle ground between visual realism and clarity of the details of depicted combat techniques (Fig. 3).

In summary, the investigated images show a number of apparent conventions forming a sui generis visual language of distortion used by the illustrators to reconcile the idiosyncrasies of the pictorial representations and their kinaesthetic source domain. In this, the presence of corrections in Cod.5278 and lack thereof in Fior di Battaglia should perhaps be interpreted as a reflection of their

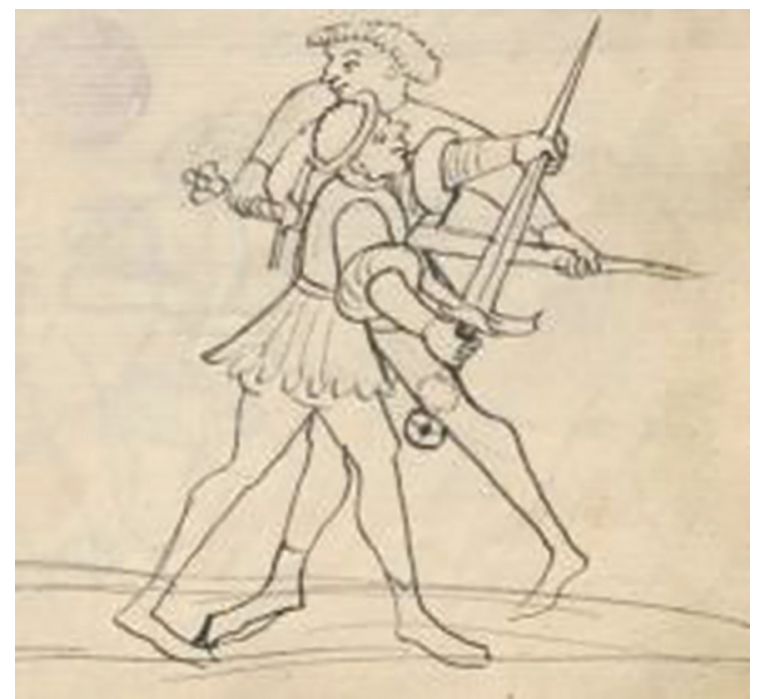

Fig. 3: Two-handed sword wrestling technique. It was coded as correction because of the visible outline betraying illustrator's initial idea of positioning the pommel of the sword near the right fighter's leg. Eventually, the pommel was repositioned and the haft elongated, presumably to emphasise how the leg should be trapped by the left fighter's sword haft. Source: Cod.5278, fol. 183r, Österreichische Nationalbibliothek, Vienna, Austria.

\footnotetext{
To clarify, the investigated sample was not random, since the images were selected from those showing combat with two-handed swords and distortions. In result, we do not include some images from Fior di Battaglia which also show wrestling and have distorted body parts. However, it bears emphasising that still Fior di Battaglia has mainly distortions in images focused on sword-fighting, while Cod.5278 - in those showing wrestling. A good example can be a comparison of folios 28r in Fior di Battaglia and 198r in Cod.5278. They show the same sword-fighting technique, but in the former the sword is distorted (elongated) whereas the latter, despite its inferior artwork, should be considered realistic.
} 
respective illustrators' competences in using the above-mentioned visual language as a pedagogical device - from this perspective, the latter work, associated with a historically attested fencing master, appears as more measured and better executed. ${ }^{2}$

The above observation points to a direct relation between the distortions and the intended purpose of the images in fight books, that is transfer of somatic knowledge (Kleinau, 2016). This notion is corroborated by the fact that weapons in our sample are always depicted in a naturalist, undistorted way when they are not involved in the imaged fighting technique, for example when a sword is dropped on the ground. Equally telling are the corrections seen in Cod.5278 which clearly reflect deliberate choices of the illustrator who sacrificed naturalism to communicate motion (Fig. 3).

\section{Transformation by Copyists}

The manuscripts used for the second study were selected according to two criteria: dependency and chronology. Firstly, both works are linked by a model-copy relationship - Paulus Hector Mair's Opus Amplissimum de Arte Athletica contains several images of sword and buckler fencing techniques which bear non-trivial visual similarity to those in the untitled fight book by master Paulus Kal, while it is also very probable that Mair, an avid collector of martial arts books, owned a copy of Kal's work (Cinato, 2016:500). Secondly, the chronological criterion was also applied to ensure that the images were copied without direct contact between the authors of the compared works - Mair was born at least two decades after master Kal's death (Tobler, 2006). It is also important to note that Paulus Kal (1420s-1480s?) was a recognised military expert hired by several courts in Germany (Welle, 1993) as well as a member of a lineage of martial arts masters (Tobler, 2006). Therefore, it seems safe to assume that he was indeed a skilled martial arts practitioner. Worth noting is also the fact that unlike most of his German predecessors who communicated their skills principally in writing, Kal opted for detailed illustrations with succinct captions (Fig. 7). Finally, the manuscript selected for this study is by all probability not the one used as a source of illustrations for Mair's compendium, but it contains all the copied images and is the only one certainly commissioned by master Kal himself (Tobler, 2006).

\footnotetext{
2 These observations could also serve as a basis for engaging the questions of illustrators' involvement in the somatic content of the images or the source of the images (copied or created for the specific source). For instance, the lack of corrections in Fior di Battaglia suggests that its images were either copied from another work/ draftbook or drawn by a competent martial artist with clear understanding of the subject matter - perhaps Fiore de'i Liberi himself (the author of the text), as he suggests in the preface that he 'can read and write and draw' (Fior di Battaglia, n.d.). On the other hand, the corrections in Cod.5278 indicate that its images were not simply copied from elsewhere, but rather created de novo or at least re-interpreted.
} 
Paulus Hector Mair (1517-1579) was a patrician of Augsburg, important member of the town's council, fencer and dedicated collector of fight books (Tobolka, 2016). As a matter of fact, his fascination with fencing and chagrin about what he perceived as decline of this 'knightly' art, combined with an incline towards living beyond his means, pushed him a little too far - between the 1540s and 1570s he spent substantial amounts of money, some of which came from embezzlement of Augsburg's town treasury, to publish three copies of a monumental martial arts compendium and purchase numerous older fight books. In 1579, his fraud was discovered and eventually led to Mair's trial and execution through hanging in the same year. Mair never referred to himself as a fencing master and admitted that he hired two experienced fencers as models for illustrations in his works (Hils, 1985:199). In his brief biography of Mair, Marek Tobolka suggests that the illustrator employed for the compendium, Jörg Breu the Younger, was also an active fencer and influenced its martial substance (Tobolka, 2016). However, he fails to present any support for this hypothesis. Hence, at the current state of research, it should be assumed that one 'cannot honestly grant [Mair] the title of master, but at best that of theorist' (Cinato, 2016:494). This would suggest that his influence on the martial content of the investigated images was insignificant and point to the hired veteran fencers and illustrator as the sources of any potential alterations between the original illustrations from Kal's fight book and their copies in Mair's work. This conclusion will be challenged later in this paper.

The qualitative content analysis performed on the images shared between these fight books revealed obvious similarities (all the images showed sword and buckler fencing and in each at least one of the swords was depicted with its point and pommel not occluded thus showing the full length of the weapon) as well as several interesting differences. The most apparent are revealed by a comparison of code frequencies between the set of original images (Kal's fight book and Breu's draft) and that of Mair's copies (Figs. 4 and 5).

First, the quality of artwork - Mair's drawings were coded as fine, that is demonstrably naturalistic by design, while the older ones are rather sketchy, even though Kal's fight book was presumably a finished work meant for selfpromotion. ${ }^{3}$ Second, while the original images have very succinct captions or none whatsoever, Mair supplements his with wordy descriptions explaining long exchanges of blows, thrusts and parries between the fencers - interestingly, at times he clearly must have misunderstood the images, as indicated by the fact that images captioned by Kal simply as a finishing position of a fencing technique from

\footnotetext{
3 While not outrightly poor, the artwork used therein is clearly subpar even for late-medieval standards, as clearly shown by two eye-catching renderings of Kal's dagger fighting illustrations of masterly quality which recently surfaced on an online auction (“Spotlight," 2018:12-13).
} 


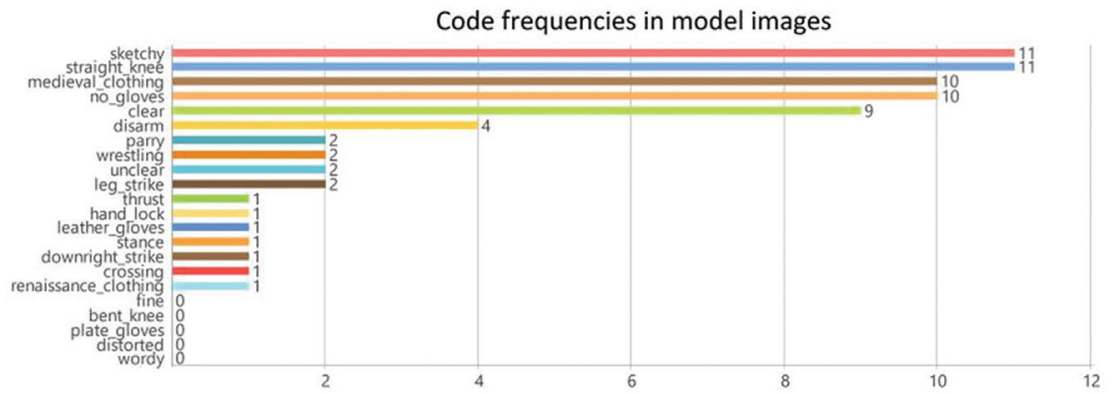

Fig. 4: Frequencies of codes in the original images from Paulus Kal's fightbook (Cgm 1507) and Jörg Breu the Younger's draftbook (Cod.I.6.2.4). Author: M. Talaga.

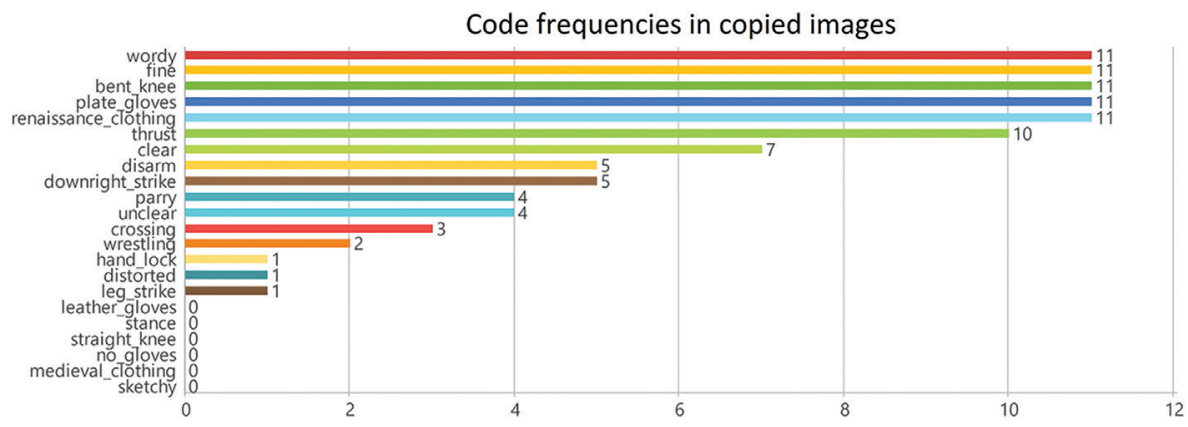

Fig. 5: Frequencies of codes in the copied images from Paulus Hector Mair's Opus Amplissimum de Arte Athletica (Cod.icon. 393). Author: M. Talaga.

the previous page, were used by Mair as depictions of separate, elaborate combat sequences. This would support the hypothesis about Mair's little involvement with the martial content of the images. Third, just as expected by Jens Peter Kleinau and Frank Cinato, illustrations in Mair's work 'update' the clothing of depicted fencers to match the latest fashion (Cinato, 2016: 494; Kleinau, 2016:109) each of them shows sixteenth-century, lavish renaissance clothing (Fig. 6) instead of plain, tight-fitting 15th-cent. medieval costumes (Fig. 7) and armoured plate gloves where no gloves were shown originally (except for one image from Breu's draftbook which has, respectively, renaissance clothing and presumably leather gloves, see Fig. 9). ${ }^{4}$ The last of the apparent differences is related to body positioning of depicted fencers - the original images show their knees to be straight, whereas their later copies have the knees bent. This detail may appear

\footnotetext{
4 Interestingly, the decision to update clothing was not entirely obvious, which is indicated by numerous drafts made by Breu in preparation for Mair's compendium which clearly show (early) medieval costumes on images copied from the 13th/14th-century fight book known as I.33. Nevertheless, their final versions consistently show up-to-date 16th-century fashion (Cinato, 2016).
} 


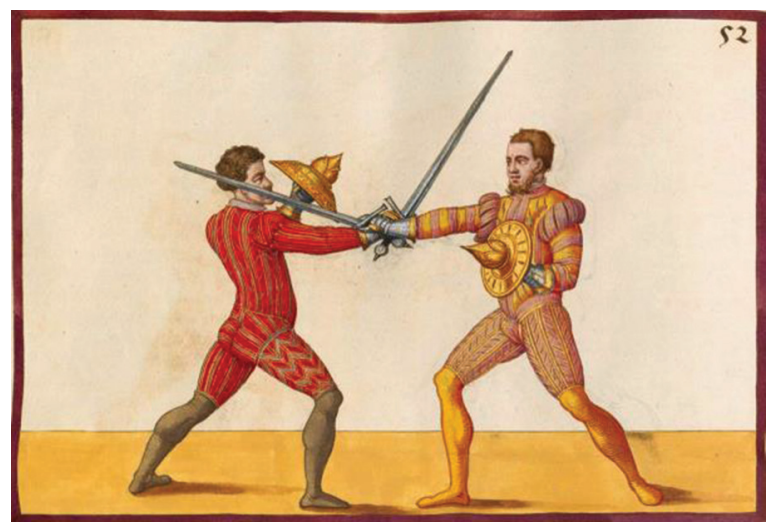

Fig. 6: Sword and buckler fencing technique involving a hand lock performed with the sword hand. It was coded as unclear, because of the ambiguity regarding positioning of the hand and weapon of the right fencer - from the image it cannot be determined whether the haft and pommel of his sword is in front or behind of his opponent's hand. The corresponding fragment of the image's caption does not solve the question ('pull your opponent's hand with the hilt and cross of your sword just behind his own pommel'). Also, note the bent knees of the fencers and the spacing between their front feet. Sources: Bayerische Staatsbibliothek München, Cod.icon. 393(2), fol. 79v (image); Paulus Hector Mair, n.d., par. 52 (translation).

to be simply stylistic, but several observations undermine such a hypothesis and shall be elaborated below.

The transition from straight to bent knees is fully consistent not only for Kal's images copied into Mair's work, but also with the vast majority of those coming from Breu's draftbook (Figs. 8 and 9). The same is true for other known copies of Kal's drawings. This would contradict Tobolka's view on illustrator's involvement in negotiating the martial content of the work (Tobolka, 2016:529) and suggests that it was not through his agency that this change was introduced - instead Mair could have insisted on it for some reason or perhaps the illustrator changed the silhouttes after seeing the hired models in motion. Both possibilities are plausible, especially given that Cinato traced a process similar to the latter in another sixteenth-century fight book inspired by much older sword and buckler fencing iconography which led him to assuming that bent knees and wider spacing between feet characterised the fencing stance typical for the second half of the sixteenth century (Cinato, 2016:502-503). This would falsify the generalisation formulated by Cinato and Kleinau that although later fight books copying older images updated their stylistic layer (clothing, equipment, landscapes and architecture), they would not alter the bodily gestures in any significant way (Cinato, 2016:502; Kleinau, 2016:93). In his comprehensive overview of the medieval and early modern German Fachliteratur related to sword and buckler fencing, Cinato uses images to argue for evolution of this martial art - the 'buckler play' would see its peak in the fourteenth century when the prevailing tendency was to keep 


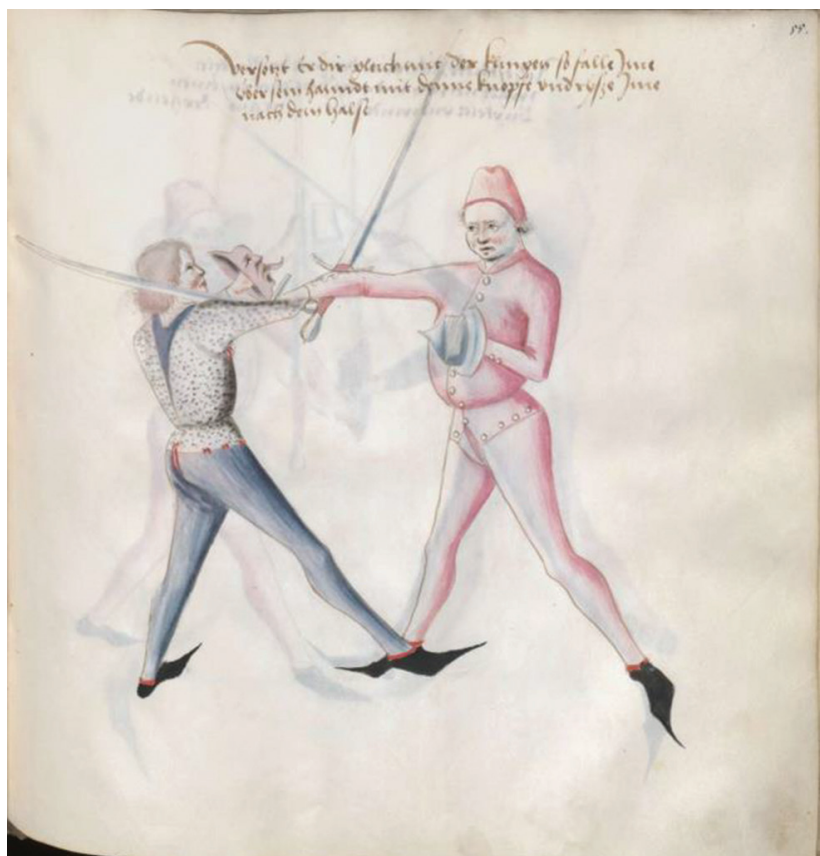

Fig. 7: Sword and buckler fencing technique involving a hand lock performed with the sword hand. Despite average artwork quality, the technical details of the hand lock are clear and consistent with the caption ('If he parries you equally with the blade, then fall over his hand with your pommel and tear after his neck'). Also, note the straight knees of the fencers and the lack of spacing between their front feet. Sources: Bayerische Staatsbibliothek München, Cgm 1507, fol. 55r (image); Paulus Kal, n.d. (translation).

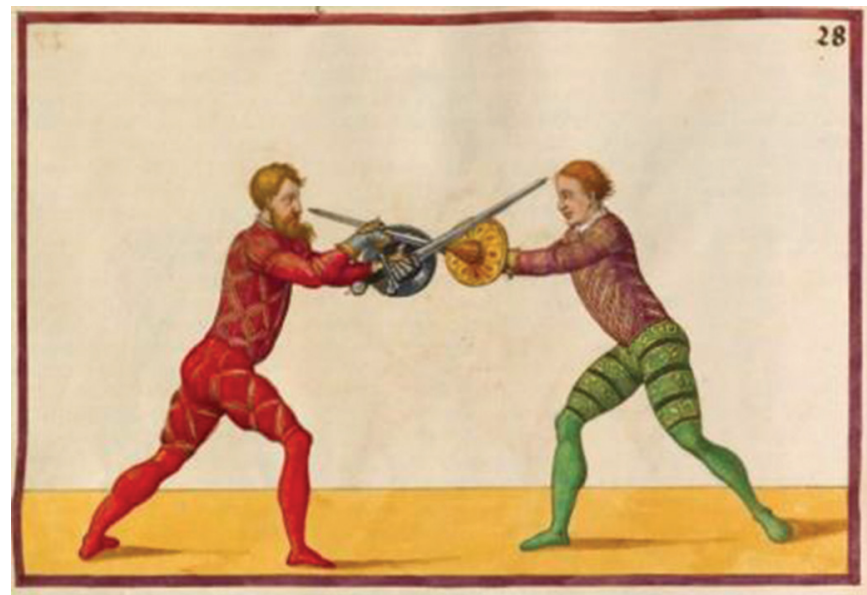

Fig. 8: Sword and buckler fencing technique involving disarming performed with the sword hand. Note the bent knees of the fencers. Sources: Bayerische Staatsbibliothek München, Cod. icon. 393(2), fol. 67v. 


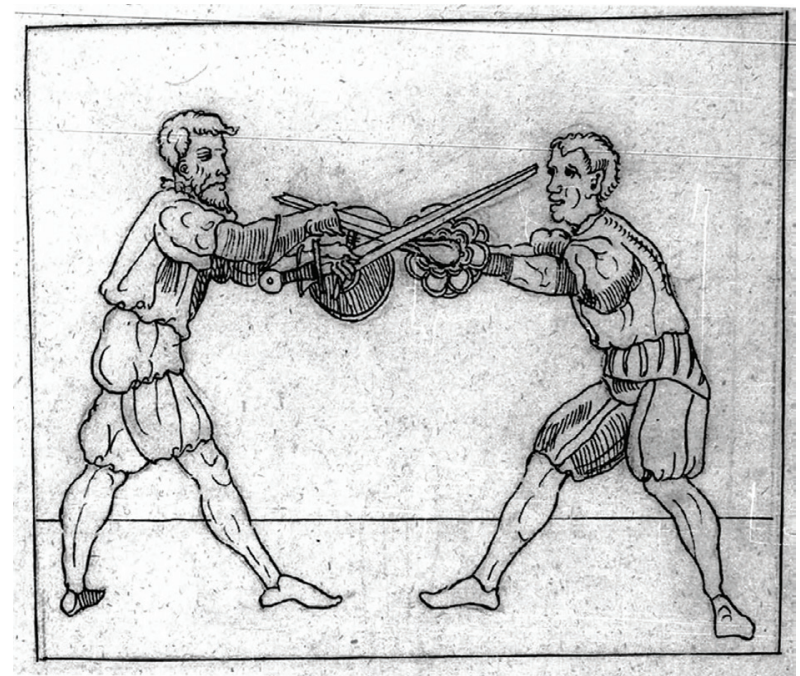

Fig. 9: Sword and buckler fencing technique involving disarming performed with the sword hand. This is a draft by Jörg Breu the Younger for his work on Paulus Hector Mair's Opus Amplimissimum de Arte Athletica based on an image from a $14^{\text {th }}$-cent. fight book (Cinato, 2016). Note that while the draft updated the clothing and equipment, it kept the straight knees of the fencers from the original image, contrary to its final rendering in Mair's book. Sources: Bayerische Staatsbibliothek München, Cgm 3712, fol. 197v.

sword and buckler hands together (Fig. 9), then gradually fell out of favour in the fifteenth century when sword and buckler hands tended to act separately (Fig. 7), only to be rediscovered by 16th-cent. fencing masters who drew inspiration from both older styles in their conceptualisation of fencing with the rapier - a new weapon that replaced the sword as the most popular side arm (Cinato, 2016: 510-511). This allows him to conclude that the process of copying of older sword and buckler images in the sixteenth century involved what could be termed two kinds of isomorphism - identity of the artefacts, that is a faithful representation of clothing, weapons, etc., and identity of martial content, that is body and weapon positioning - and to state, with the above in mind, that 'when Mair uses a fourteenth-century image as a model, even if adapted to the contemporary tastes in clothing, the resulting image is lagging concerning the reality of the practice in its time' (Cinato, 2016:502). Combined with the fact that Mair's images are more often unclear in their correspondence with the wordy accompanying texts than their older counterparts, this corroborates Cinato's view on Mair as a mere theorist and places his compendium well within Kleinau's category of fight books meant for delectare - those whose martial content was at best secondary to their aesthetic and prestige-building functions (Kleinau, 2016:93).

However, the consistent transition from straight knee stance in older images to bent knee stance in Mair's compendium (Fig. 10), as well as noticeable differences 


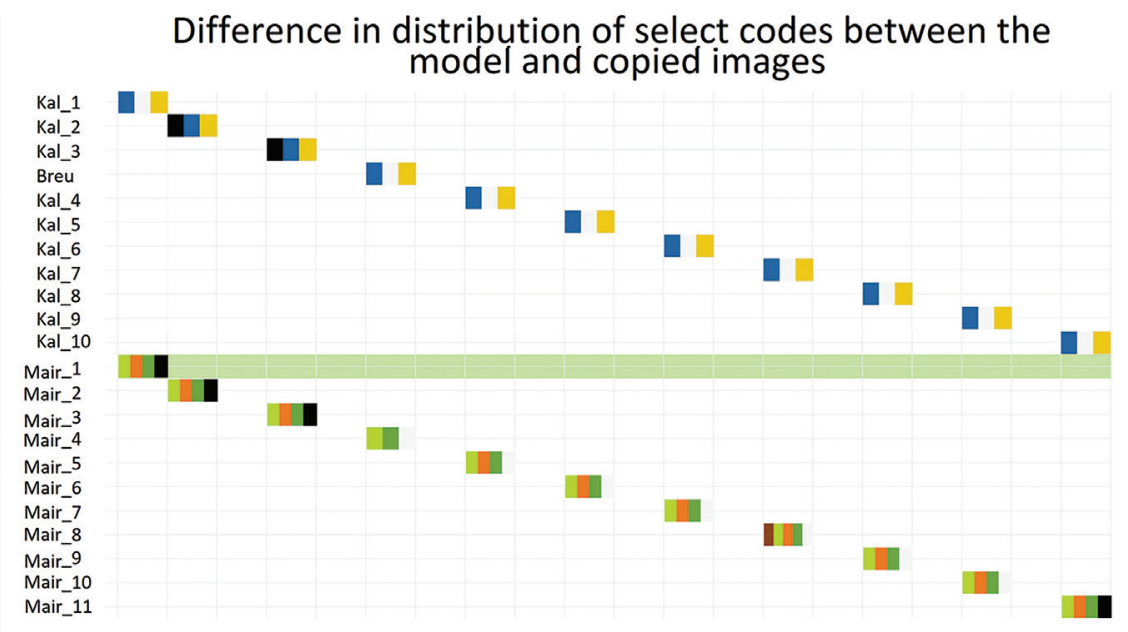

Fig. 10. Distribution of select codes in the original images from Paulus Kal's fightbook (Cgm 1507), Jörg Breu the Younger's draftbook (Cod.I.6.2 .4) and copied images from Paulus Hector Mair's Opus Amplissimum de Arte Athletica (Cod.icon. 393). Key to colours: blue: sketchy; orange: fine; white: clear; black: unclear; yellow: straight knee; dark green: bent knee; light green: wordy; brown: distorted. The green line in the middle of the graph separates the sets of model and the copied images. Author: M. Talaga.

in spacing between depicted fencers (Figs. 4 and 5) falsifies the conclusion that copying left the body positions unaffected. As shown by modern archaeological experimentation or historical dance studies, such iconographical details often heavily influence the dynamics of motion reconstructed from them (Jaquet, 2016). If this modification were attributed to Mair and interpreted as an attempt to enhance the practicality of the old techniques, this could rehabilitate his reputation as an original contributor to a martial discourse of his time. Alternatively, it could mean that the fencers hired by him as models unpromptedly performed the old fencing techniques in a modified way, more compatible with 16th-cent. fashion, which was then captured by the illustrator. In evaluating these two hypotheses, which are not mutually exclusive, ${ }^{5}$ a potentially important piece of the puzzle comes from an influential fight book published in 1516, a year before Mair's birth Ergrundung Ritterlicher Kunst der Fechterey by Andre Paurnffeyndt. This work is not only regarded as the first printed fight book (Anglo, 2000:46) but also the only one known so far whose stated purpose was to serve novices learning how to fight. Interestingly, the first of his 'Twelve Rules for the Beginner Fencer' states that 'whichever leg stands forward is bowed. The hind outstretched supports the

\footnotetext{
5 If Mair was not completely disinterested in martial content of the illustrations, the change made by the illustrator observing the fencers would not go unnoticed and its presence in the final version of the work would still require Mair's consent.
} 
body above' (Andre Paurnffeyndt, n.d.), which would be an apt description of the body positions shown in Mair's work. On the same accord, Mair could be familiar with Paurnfeyndt's teachings since the print was easily available and his collection included a later handwritten copy of it (Paulus Hector Mair, n.d.). ${ }^{6}$ Moreover, the application of such body positioning to each of his sword and buckler images, and virtually all images in his compendium, seems somewhat dogmatic, as it sometimes results in awkward body mechanics, especially when pulling motion is involved - unlike Mair, both older images (Figs. 4 and 6) and 16th-cent. fight books tend to show pulling combined with shifting the body weight towards the back leg, which is natural for humans, while the forward lean and loaded front leg is characteristic for pushing. This suggests that the transition from straight to bent knees did not result solely from observing the hired fencers, but rather from Mair who had the illustrator alter his drafts, to make them compatible with Paurnffeyndt's advice. Whether Mair treated it as a way to show his erudition as a martial artist or simply as another layer of his work's aesthetics remains unknown. But either way, deliberately or not, by changing the body positioning of the fencers Mair changed the kinaesthetic content of the original images and discarded a whole body of somatic knowledge related to it effectively robbing his readers from the chance to access the old fencing techniques which he tried to preserve. ${ }^{7}$

Additional insights are provided by an analysis of less apparent connections between the coded features of the investigated pairs of images. When the similarities between the models and copies as well as the differences related to aesthetics (clothing etc.) are put aside, what remains reveals an interesting pattern - while Mair's work is clearly superior in terms of artwork quality (coded as fine) and sophistication of captions explaining the fencing technique behind the illustrations (wordy), it also contains more images whose translation into actual fencing moves is ambiguous (unclear) (Fig. 7). Also, the only evidently distorted image from the investigated sample comes from Mair (pair \#8, see Table 1) - due to significantly larger spacing between the fencers in the copied image, the fencer performing a disarming technique is depicted with disproportionally elongated right arm. The interplay between the images and text is also interesting. As already mentioned, Mair added complicated sequences of motions to drawings which originally were just end positions of previous fencing techniques (Table 1: pairs \#9 and \#11) or fixed stances (Table 1: pairs $\# 3$ and \#5). He also significantly expanded the length and diversity of combat techniques ascribed to the remaining images - the frequency of thrusts is

\footnotetext{
6 However, it remains uncertain whether Mair had a chance to read 'the Twelve Rules' already in the 1540 s when he was working on his Opus Amplissimum.

Mair made it explicit in his preface (Paulus Hector Mair, n.d.).
} 
particularly telling, as Mair have ten of them mentioned in the captions while Kal depicts but one (Figs. 4 and 5). This suggests that he copied the images, but mostly invented or patchworked the captions himself - again, not a conduct expected from a competent fencing master. In addition, with such sophisticated descriptions it is often difficult to determine which stage of the fencing sequence is the image referring to. ${ }^{8}$ This indicates that neither naturalism of images nor volume of textual explanations automatically enhance knowledge transmission or indicate high competences of the author. It also suggests that the final appearance of the images in Opus Amplimissimum resulted from a negotiation between the source images, tastes of the contemporary audience, illustrator, model fencers and Mair - a negotiation sometimes resulting in suboptimal compromises.

\section{Conclusions}

The present study supports the generalisations coined in previous scholarship stating that the material source domain is 'remembered (not reproduced) in a pictorial image' (Ventrone, 1991:11) and that when an image is transferred from one medium to another it is 'a transmission and not a copy of the original' (Kleinau, 2016:109). In Gestalt terms, it could be paraphrased that historical visuals aimed at mediating embodied knowledge or technique (Spatz, 2015:41) are crafted so as to preserve the whole of its epistemic content, not its physical manifestation. To this end, naturalism is partially abandoned in favour of introducing distortions which disrupt the anatomical feasibility of the depiction (let us call it the static Gestalt), but help capture important kinaesthetic or spatial aspects of the motion it represents (dynamic Gestalt). However, the reader of such images interested in reconstructing the motion they convey cannot access the dynamic Gestalt directly, but only through interpretation of its static parts, that is through 'a kind of perceptual inference' (Spelke, 1990:30). As shown by the case of copying images between 15th-cent. and 16th-cent. martial arts treatises, such inference is problematic even when the source and the reader are relatively close to each other in terms of time and culture and when actual physical experimentation is used to reconstruct the somatic content of images. Details which may seem unimportant from the illustrator's perspective, such as positioning of the knee of a fencer, can result in significant change in the Gestalt perceived by the reader. Conversely, distortions which from the reader's perspective may look as mere mistakes or negligences of the illustrator without bearing for the Gestalt of the image may well be deliberate modifications aimed at knowledge transmission.

\footnotetext{
8 In fact, images used as notations of motion may sometimes show multiple stages of the same movement in a single image, thus adding another layer of complication for researchers (Kleinau, 2016). However, no examples of such treatment were found in the discussed sample.
} 
In other words, we propose that although the fight book illustrations are not strictly isomorphic with the depicted corporeal and material reality, they allow for mapping their visual features on complex kinaesthetic processes (martial arts techniques) often impossible to efficiently document in a naturalist image. Hence, they should be considered as isomorphic with their source domain in a loose, allegorical manner (Isaac, 2019) in which naturalism is abandoned in favour of preserving the whole (Gestalt) of the kinaesthetic content, not the details of its static visual manifestation.

\section{Summary}

Several subdisciplines within historiography, most notably the arms and armour or martial arts studies, are interested in inferring physical qualities of historical material objects from historical sources. Scholars from these fields face serious deficiency of written accounts when it comes to various crucial information regarding their subject matter. Therefore, researchers' attention is often drawn to iconographical sources, sometimes resulting in certain fascination with the material culture depicted in primary technical literature (Fachliteratur). This tendency seems particularly strong in studies on HEMA which rely heavily on pre-modern combat treatises known as 'fight books' (Fechtbü̈cher) and are tempted either to treat the available iconography as a faithful representation of its corresponding material reality or to interpret apparent mismatch between iconographical representations and their material source domain as evidence for the inferior skills of the illustrator.

We would like to put forward that there is a fundamental oversight in such approach to Fachliteratur in general and fight books in particular, namely the lack of consideration for the artwork as a diagrammatic representation of the functional aspects of depicted embodied technique, where proportional 'realism' is of lesser priority. It may be fruitful to develop a more nuanced method of 'reading' such images. Our survey of select latemedieval fight books shows that equipment, and even body parts, are regularly distorted in their depictions in the fight books to better communicate the subject matter, especially where textual descriptions would be complicated. Interpreted in Gestalt terms, this phenomenon may serve as an example of historical pragmatic application of the cognitive principle of holism - that the whole is something different than the sum of its parts.

Keywords: Visual language, notation of motion, middle ages, martial arts studies, holism.

\section{Historisches Bildmaterial und die Rekonstruktion von Bewegung.}

\section{Eine Gestaltperspektive auf die mittelalterliche Ikonographie des Fechtens}

\section{Zusammenfassung}

Mehrere Teildisziplinen der Historiographie, insbesondere die Waffen- und Rüstungswissenschaft oder die Kampfkunstforschung, sind daran interessiert, physikalische Eigenschaften historischer Materialobjekte aus historischen Quellen abzuleiten. Wissenschaftler aus diesen Bereichen sind mit einem erheblichen Mangel an schriftlichen Berichten 
konfrontiert, wenn es sich um verschiedene wichtige Informationen zu ihrem Thema handelt. Daher wird die Aufmerksamkeit der Forscher oft auf ikonographische Quellen gelenkt, was manchmal zu einer gewissen Faszination für die in der Fachliteratur dargestellte Materialkultur führt. Diese Tendenz scheint besonders ausgeprägt in Studien über die historischen europäischen Kampfkünste (HEMA-historical European martial arts) zu sein, die sich stark auf vormoderne Kampftraktate stützen, die als "Fechtbücher" bekannt sind und versuchen, die verfügbare Ikonographie entweder als treue Darstellung ihrer entsprechenden materiellen Realität zu behandeln oder scheinbare Diskrepanzen zwischen ikonographischen Darstellungen und ihrem materiellen Quellbereich als Beweis für die unterlegenen Fähigkeiten des Illustrators zu interpretieren. Wir möchten darauf hinweisen, dass es ein grundlegendes Versehen in einem solchen Ansatz für Fachliteratur im Allgemeinen und Fechtbücher im Besonderen gibt, nämlich die fehlende Berücksichtigung des Kunstwerks als schematische Darstellung der funktionalen Aspekte der dargestellten verkörperten Technik, bei der der proportionale "Realismus" von geringerer Priorität ist. Es kann fruchtbar sein, eine differenziertere Methode zum "Lesen" solcher Bilder zu entwickeln. Unsere Übersicht über ausgewählte spätmittelalterliche Fechtbücher zeigt, dass Ausrüstung und sogar Körperteile in ihren Darstellungen in den Fechtbüchern regelmäßig verzerrt sind, um die Thematik besser zu vermitteln, insbesondere dort, wo textliche Beschreibungen kompliziert wären. In Gestaltbetrachtung interpretiert, kann dieses Phänomen als Beispiel für eine historisch-pragmatische Anwendung des kognitiven Prinzips des Holismus dienen - dass das Ganze etwas anderes ist als die Summe seiner Teile.

Schlüsselwörter: Bildsprache, Bewegungsnotation, Mittelalter, Kampfkunststudium, Holismus.

\section{References}

Andre Paurñfeyndt (n.d.). In Wiktenauer (C. Trosclair, Trans.). Retrieved from https://wiktenauer.com/wiki/ Andre_Paur\%C3\%B1feyndt (Accessed January 4, 2020).

Anglo, S. (2000). The martial arts of renaissance Europe. London, UK: Yale University Press.

Basing, P. (1990). Trades and crafts in medieval manuscripts. New Amsterdam, UK: British Library.

Burkart, E. (2016). Limits of understanding in the study of lost martial arts. Acta Periodica Duellatorum, 4(2), $5-30$.

Cinato, F. (2016). Development, diffusion and reception of the "Buckler Play": A case study of a fighting art in the Making. In D. Jaquet, K. Verelst, T. Dawson (Eds.), Late medieval and early modern fight books. Transmission and tradition of martial arts in Europe (14th-17th centuries) (pp. 481-546). Leiden-Boston, Netherlands: Brill.

Farrell, K. (2017). The Kölner Fechtbuch: Context and comparison. Acta Periodica Duellatorum, 7(1), $203-235$.

Fior di Battaglia (n.d.). In Wiktenauer (C. Hatcher, Trans.). Retrieved from https://wiktenauer.com/wiki/Fior_ di_Battaglia_(MS_Ludwig_XV_13). (Accessed January 4, 2020)

Heider, F. (1959). Thing and medium. On perception and event structure, and the psychological environment. Psychological Issues, 1(Monograph 3), 1-34.

Hils, H.-P. (1985). Meister Johann Liechtenauer Kunst des Fechtens. Frankfurt-am-Main, Germany: Peter Lang.

Isaac, A. M. C. (2019). The allegory of isomorphism. AVANT - Trends in Interdisciplinary Studies, 10(2), doi: 10.26913/avant.2019.02.05

Jaquet, D. (2016). Experimenting historical European martial arts, a scientific method? In D. Jaquet, K. Verelst, T. Dawson (Eds.), Late medieval and early modern fight books. Transmission and tradition of martial arts in Europe (14th-17th centuries) (pp. 216-243). Leiden-Boston, Netherlands: Brill.

Kleinau, J. P. (2016). Visualised motion: Iconography of medieval and renaissance fencing books. In D. Jaquet, K. Verelst, T. Dawson (Eds.), Late medieval and early modern fight books. Transmission and tradition of martial arts in Europe (14th-17th centuries) (pp. 88-116). Leiden-Boston, Netherlands: Brill. 


\section{GESTALT THEORY, Vol. 42, No.2}

Köhler, W. (1938). The place of value in the world of facts. New York, NY: Liveright.

Ławrynowicz, O., \& Nowakowski, P. A. (2009). Stove tiles as a source of knowledge about mediaeval and early modern arms and armour. Studies in Post-Medieval Archaeology, 3, 303-316.

Lehar, S. (1999). Gestalt isomorphism and the quantification of spatial perception. Gestalt Theory, 21, 122-139.

Löwgren, J., \& Stolterman, E. (2004). Thoughtful interaction design: A design perspective on information technology. Cambridge, MA: MIT Press.

Paulus Hector Mair (n.d.). In Wiktenauer (K. P. Myers \& P. M. Haaland, Trans.). Retrieved from https://wiktenauer.com/wiki/Paulus_Hector_Mair. (Accessed January 4, 2020).

Paulus Kal (n.d.). In Wiktenauer (C. Winslow, Trans.). Retrieved from https://wiktenauer.com/wiki/Paulus_ Kal. (Accessed January 4, 2020).

Spatz, B. (2015). What a body can do. Technique as knowledge, practice as research. London, UK: Routledge.

Spelke, E. S. (1990). Principles of object perception. Cognitive Science, 14(1), 29-56.

Spotlight. A Taste of TEFAF Maastricht (2018). Retrieved from https://guenther-rarebooks.com/usr/documents/spotlights/document_url/49/spotlight-taste-of-tefaf-2018-miniatures.pdf

Steinman, R. M., Pizlo, Z., \& Pizlo, F. J. (2000). Phi is not beta, and why Wertheimer's discovery launched the Gestalt revolution. Vision Research, 40(17), 2257-2264.

Tilley, C. (2014). Material culture and text: the art of ambiguity. London, UK: Routledge.

Tobler, C. H. (2006). In service of the duke: The 15th century fighting treatise of Paulus Kal. Highland Village, TX: Chivalry Bookshelf.

Tobolka, M. (2016). Paulus Hector Mair (ca 1517-1579). Studia Historica Nitriensia, 20(2), 525-530.

Ventrone, P. (1991). On the use of figurative art as a source for the study of medieval pectacles. Comparative Drama, 25(1), 4-16.

Welle, R. (1993). “...und wisse das alle höbischeit kompt von deme ringen”. Der Ringkampf als adelige Kunst im 15. Und 16. Jahrhundert. Eine sozialhistorische und bewegungsbiographische Interpretation aufgrund der Handschriften und gedruckten Ringlehren des Spätmittelalters. Forum für Sozialgeschichte, 4, 243-253.

Żygulski, Z. (1984). Armour as a symbolic form. Waffen und Kostümkunde, 26, 77-96.

Maciej Talaga - Maciej Talaga received his MA in archaeology in 2012 and joined the 'Nature-Culture' PhD programme at the University of Warsaw in 2018. For the last decade, his research interests have revolved around pre-modern European martial traditions, with particular focus on late-medieval Central Europe and the socalled 'German school of fighting' (Kunst des Fechtens). Having initially approached the topic from a purely archaeological perspective, he gradually adopted a performative approach combining text- and artefact-based studies with practical experimentation.

Address: Jaworowa 8, 05-807 Żółwin, Poland.

E-mail: m.talaga@al.uw.edu.pl

Harrison Ridgeway studied Digital Art at the RMIT Melbourne and Illustration at the Chisholm Institute, with practical training in several traditional printing, painting, and drawing media. He is currently occupied as an artist-generalist working digitally, and since becoming involved in the historical fencing community, he has prepared related artwork for a number of published books including one of his own.

Address: 99a koornang road, Carnegie Victoria 3163, Australia.

E-mail: harrywerke@gmail.com 


\section{APPENDIX}

All the manuscripts and images used for the case studies described in this paper are available online in a web-based repository: https://wiktenauer.com

The qualitative content analyses were performed on the above-mentioned by two coders (authors of this paper) and cross-checked for consistency. In result the following codebooks emerged:

\section{Study on distortions: MS XV 13 (Fior di Battaglia) and Cod.5278 (untitled).}

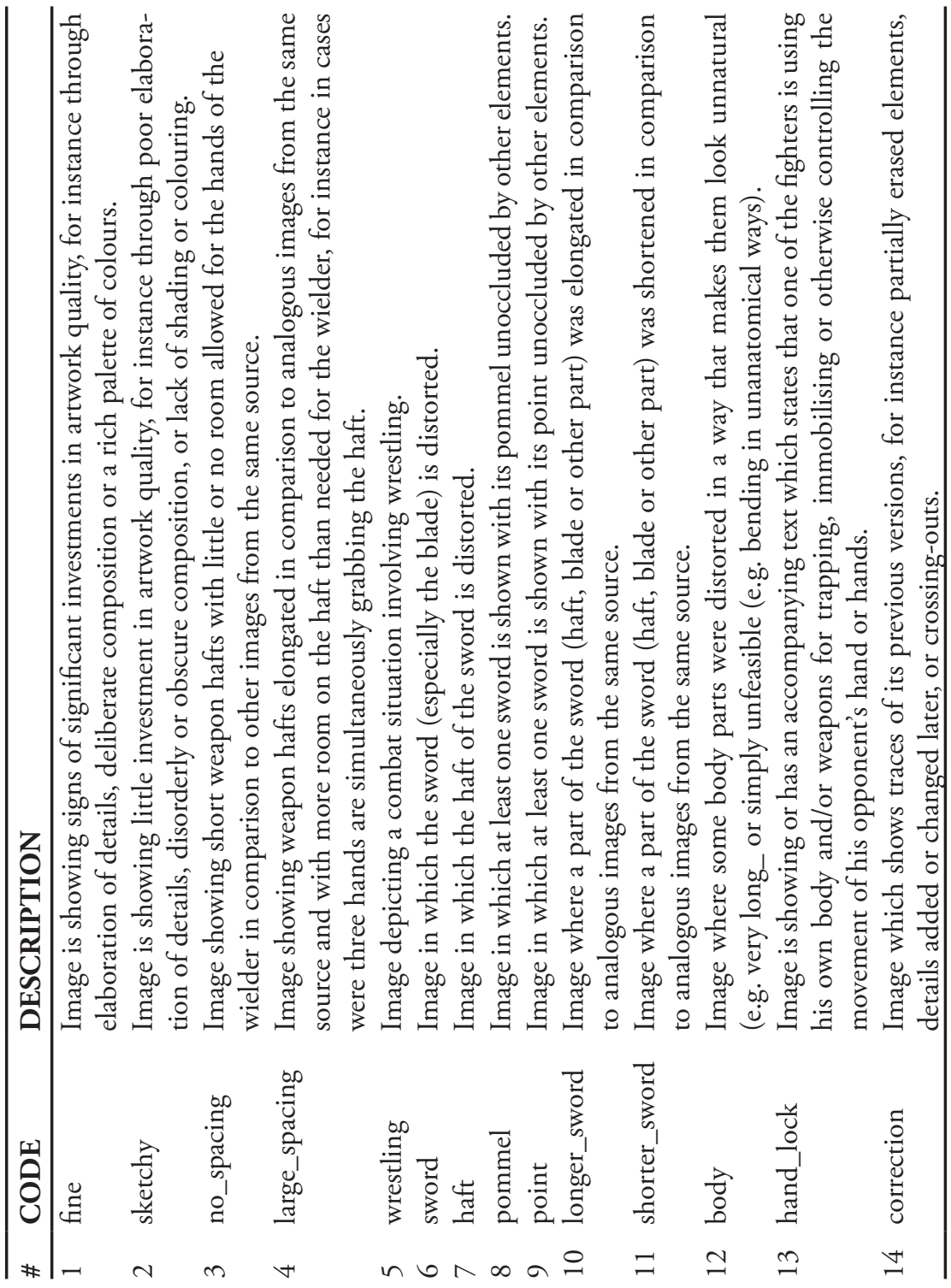




\section{Study on copying: Cod.icon. 393 (Opus Amplissimum de Arte Athletica) and Cgm 1507 (untitled).}

This study inherited all the codes (14) and descriptions from the first one (see above). In addition, it introduced the following new items into the codebook:

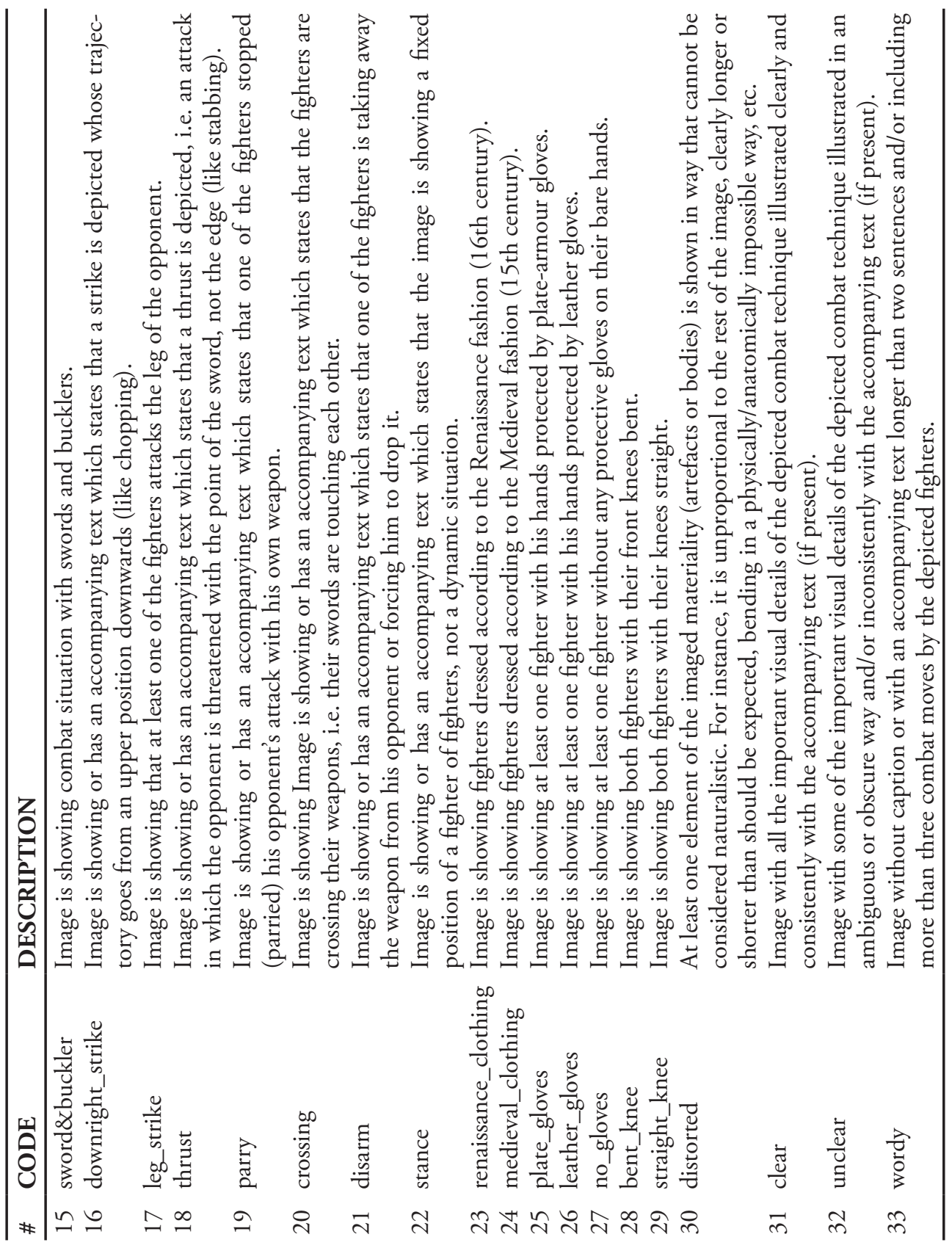

